\title{
THE IMPACT OF THE STRUCTURAL FORM ON THE STRESS DISTRIBUTION IN A FLEXSPLINE OF A HERMETIC HARMONIC DRIVER
}

\author{
JACEK PACANA \\ Rzeszow University of Technology, Faculty of Mechanical Engineering and Aeronautics, Rzeszow, Poland \\ e-mail: pacanaj@prz.edu.pl
}

\begin{abstract}
This paper presents a comparative analysis with different models of the flexspline for a harmonic hermetic drive. The flexspline is a thin-walled construction, deforming during work, so its design is a very complicated process. The paper contains a strength analysis for some selected models of this gear. Calculations were performed using the finite element method (FEM) in ADINA. The work presents stress diagrams in longitudinal intersections for susceptible wheels of different shapes for direct comparison. Suggested changes in construction of the flexspline will increase durability of a welded hermetic gear.
\end{abstract}

Keywords: flexspline, harmonic drive, stress analysis, finite element method (FEM)

\section{Introduction}

Harmonic drives have been very popular for nearly 50 years, i.e. from the moment they were granted a patent. Since that time, a lot of new structural and technological solutions have been presented in synthetic monographs (Mijał, 1999; Ostapski, 2001). Other publications have frequently discussed the geometry of elements of the drive, especially flexsplines, or the possibility of changing the parameters of toothed rims (Ishikawa, 1967; Musser, 1960; Muller and Wilk, 1965). The material and exploitation issues of the drive were presented (Dudley, 1962) as well as the examples of its application with a great focus on flexsplines. The issues related to the calculation of the load applied to the flexspline and strength calculations have been discussed in the monographs mentioned above as well as in other papers (Budzik et al., 2009; Gravagno et al., 2016; Kayabasi and Erzincanli, 2007). More recent papers include numerical analysis of the optimization of both - the parameters of a toothed rim as well as the shape of the body of a flexspline, mainly with the use of the FEM method (Folęga, 2015; Kikuchi et al., 2003; Kleiber and Zacharski, 1983) and the boundary element method (Folega, 2009; Li, 2016). Only a few articles (Jeon and Oh, 1999; Pacana, 2018; Pacana and Markowska, 2016; Tjahjowidodo et al., 2013) present conduction and results of stationary research on an actual harmonic drive related to calculation of stress in elements of the drive and its durability. The vast majority of papers present issues concerning typical harmonic drives with a short flexspline of an annular type. In the available literature, there are only few publications on hermetic harmonic drives, and the majority of the authors only mention them without giving any further description.

A number of papers (Mijał, 1996, 1999; Mijał and Pacana, 2004) present recommended geometrical parameters and the course of calculations for an hermetic harmonic drive. The problems with the optimization of shape of the flexspline were discussed in the paper by Danilov (1983), but the discussion only referred to the impact of the generator with the omission of torque it carries. Having consideration to the advantages of harmonic drives such as: possibility of achieving considerable velocity ratios at one degree, low rubbing speed in the meshing area, light load on a shaft with a bending force, considerable kinematic accuracy as well as a silent-running characteristic, the analysis of the problem is justified and a wider range of applications 
should be looked for. Hermetic harmonic drives can be used in the situation when the airtightness needs to be maintained when propulsion is carried from one separate workspace to another. At the same time, hermetic harmonic drives retain all the above mentioned advantages of a classic harmonic drive. Therefore, knowing what problems of the drive are, the structure needs to be improved in order to increase its durability and longevity. It is a difficult task in the case of the flexspline of an hermetic harmonic drive because of its structure and the character of operation.

\section{Description of the structure}

A classic harmonic drive consists of a flexspline, a rigid gear and a generator (PN-79/N-88514). The rule of operation of the harmonic drive is based on the assumption that the relative motion of the mating gears results from elastic deformations of one of them. The gear deformed by the wave generator is called the flexspline (2) and the mating internally toothed gear is called the rigid gear (3). The generator (1) causes the travelling of deformation waves along the perimeter of the flexspline carrying motion onto the mating flexspline or the rigid gear. The toothed rims of the flexspline and rigid gear mesh in the meshing areas, whereas in the remaining fragments the gear teeth pass one another. Each of the three basic elements of the drive can be driven or have a driving torque, and the drive can operate as a reducer, multiplier or a differential gear.

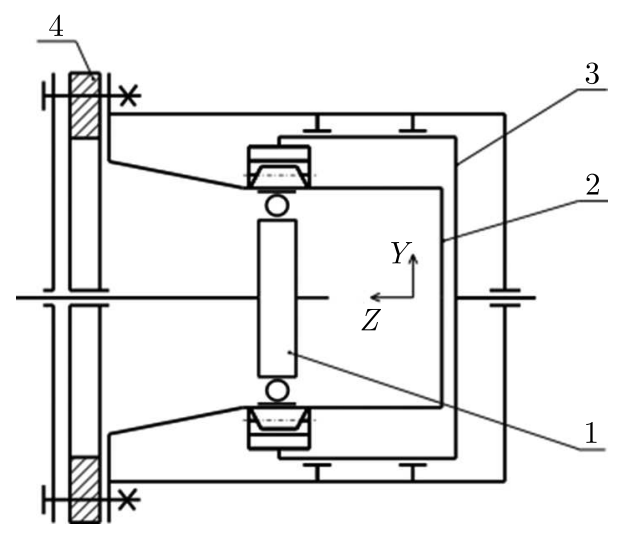

Fig. 1. An outline of the hermetic harmonic drive (as described in the text)

The hermetic harmonic drive (Fig. 1) consists of the same basic elements, i.e. a generator (1), a flexspline (2) and a rigid gear (3). However, it differs from the classic solutions in that it has a considerably longer flexspline with the bottom at one end and the flange at the other end. The flange is attached to the hermetic partition (4), ensuring airtightness of the drive.

Due to the expected special features, the flexspline of the hermetic harmonic drive is very difficult to design. It should be flexible and elastic enough so that it can be deformed and, at the same time, rigid enough so that it can carry the load with a specified torque. That is why the element is so long and the toothed rim is located in the middle of its length. Figure 2 presents classic shape of the flexspline of the hermetic harmonic drive together with geometrical parameters, based on the literature (Mijał, 1999; Ostapski,2011).

The recommended values of the geometrical parameters are presented marked in Figure 2.

Figure 2 shows that the flexspline of the hermetic harmonic drive consists of three characteristic sections: a toothed rim, a conical part between a flange and a rim and a cylindrical part between the rim and the bottom. Thickness of the gear body under the toothed rim $h_{1}$ is insignificant because the gear must be deformed by the generator. The conical part, which carries the torque, is thicker than the cylindrical part and the bottom of the gear. They both ensure the airtightness of the space which receives the load. The gear can be either uniform or with a welded bottom (Mijał and Pacana, 2004). 


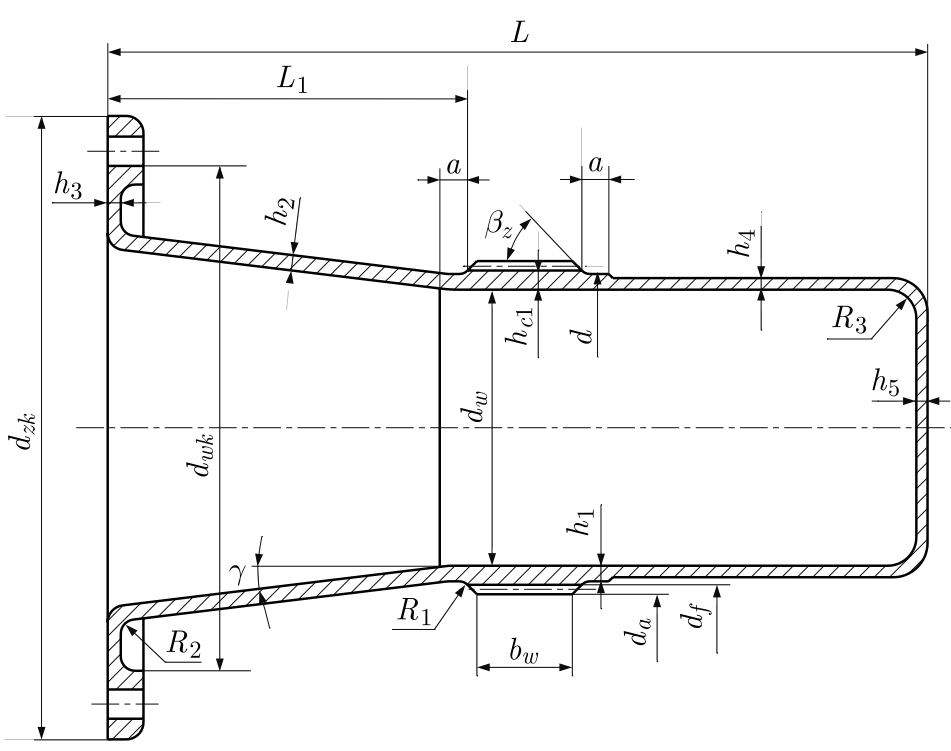

\begin{tabular}{|c|c|}
\hline Parameter & Dimension \\
\hline$d_{1}$ & \multirow{4}{*}{$\begin{array}{l}\text { calculated } \\
\text { by the } \\
\text { formulas }\end{array}$} \\
\hline$d_{r 1}$ & \\
\hline$d_{a 1}$ & \\
\hline$m$ & \\
\hline$h_{c 1}$ & {$[1.5 \mathrm{~m}, 1.8 \mathrm{~m}]$} \\
\hline$d_{w}$ & $d_{r 1}-2 h_{c 1}$ \\
\hline$d_{w k}$ & $\geqslant 1.3 d_{1}$ \\
\hline$\overline{d_{z k}}$ & {$\left[1.8 d_{1}, 2 d_{1}\right]$} \\
\hline$h_{1}$ & {$\left[0.005 d_{1}, 0.015 d_{1}\right]$} \\
\hline$h_{2}$ & $\leqslant h_{1}-0.2 m$ \\
\hline$h_{3}$ & {$\left[1 h_{2}, 1.2 h_{2}\right]$} \\
\hline$h_{4}=h_{5}$ & {$\left[0.2 h_{1}, 0.5 h_{1}\right]$} \\
\hline$R_{1}$ & {$\left[0.03 d_{1}, 0.05 d_{1}\right]$} \\
\hline$R_{2}$ & {$\left[3 h_{2}, 4 h_{2}\right]$} \\
\hline$R_{3}$ & [2 mm, $3 \mathrm{~mm}]$ \\
\hline$\beta_{z}$ & {$\left[30^{\circ}, 45^{\circ}\right]$} \\
\hline$\gamma$ & {$\left[6^{\circ}, 12^{\circ}\right]$} \\
\hline$b_{w 1}$ & {$\left[0.1 d_{1}, 0.35 d_{1}\right]$} \\
\hline$a$ & {$\left[0.03 d_{1}, 0.05 d_{1}\right]$} \\
\hline$L$ & {$\left[2 d_{1}, 2.4 d_{1}\right]$} \\
\hline$L_{1}$ & {$\left[0.8 d_{1}, 1 d_{1}\right]$} \\
\hline
\end{tabular}

Fig. 2. Parameters of the flexspline of the hermetic harmonic drive

It is difficult to construct the flexspline of the hermetic harmonic drive due to its relatively insignificant wall thickness, length of the sleeve and the bottom at its end. Therefore, roughing and finishing of the outer surfaces as well as tooth cutting is performed after mounting the gear on the mandrel of a special processing device.

\section{Calculation model}

Due to necessity of using a great number of finite elements, calculations with the use of three-dimensional models are time-consuming and they require the use of great computing power. Due to its complicated shape, the highest density of the elements occurs in the toothed rim of the flexspline model. That is why the three-dimensional model was simplified in a way that the toothed rim was replaced with an equivalent ring. Depth of the stress residual in teeth as well as results of the previously conducted two-dimensional analysis of the toothed rim were also taken into account (Budzik and Pacana, 2005). Apart from the toothed rim, the precise representation of the actual shape of the flexspline was maintained. This simplification allowed one to considerably limit the number of finite elements used in discretization of the flexspline. Because in calculations a three-dimensional model with simplifications was used, could be applied quadratric cubic elements for discretization. The simplified form of the flexspline made it easier to divide the model into finite elements and allowed them to be arranged. In areas where higher stress values were expected, a mesh of finite elements with a much higher density was used than in other parts of the model.

Based on the author's own experience described in monograph (Pacana, 2018), and the publications of other authors (Folęga, 2015; Ostapski, 2011), the greatest risk of damage occurs at the thickness change near the toothed rim and on the radius between sections of the flexspline. Also, the influence of mesh density on quality of the obtained results was verified by the author and presented in the article (Pacana and Budzik, 2008). The highest density of finite element mesh nodes was assumed in these places. 
Thanks to the modification of the calculation model it was possible to make the calculation batch file smaller. This allowed one to increase the scope of calculations through introduction of a few various models and making use of contact elements between the flexspline and the generator. Due to symmetry of deformation of the flexspline during operation, a threedimensional flexspline model was used and it corresponded to its half only. It is presented in Fig. 3.

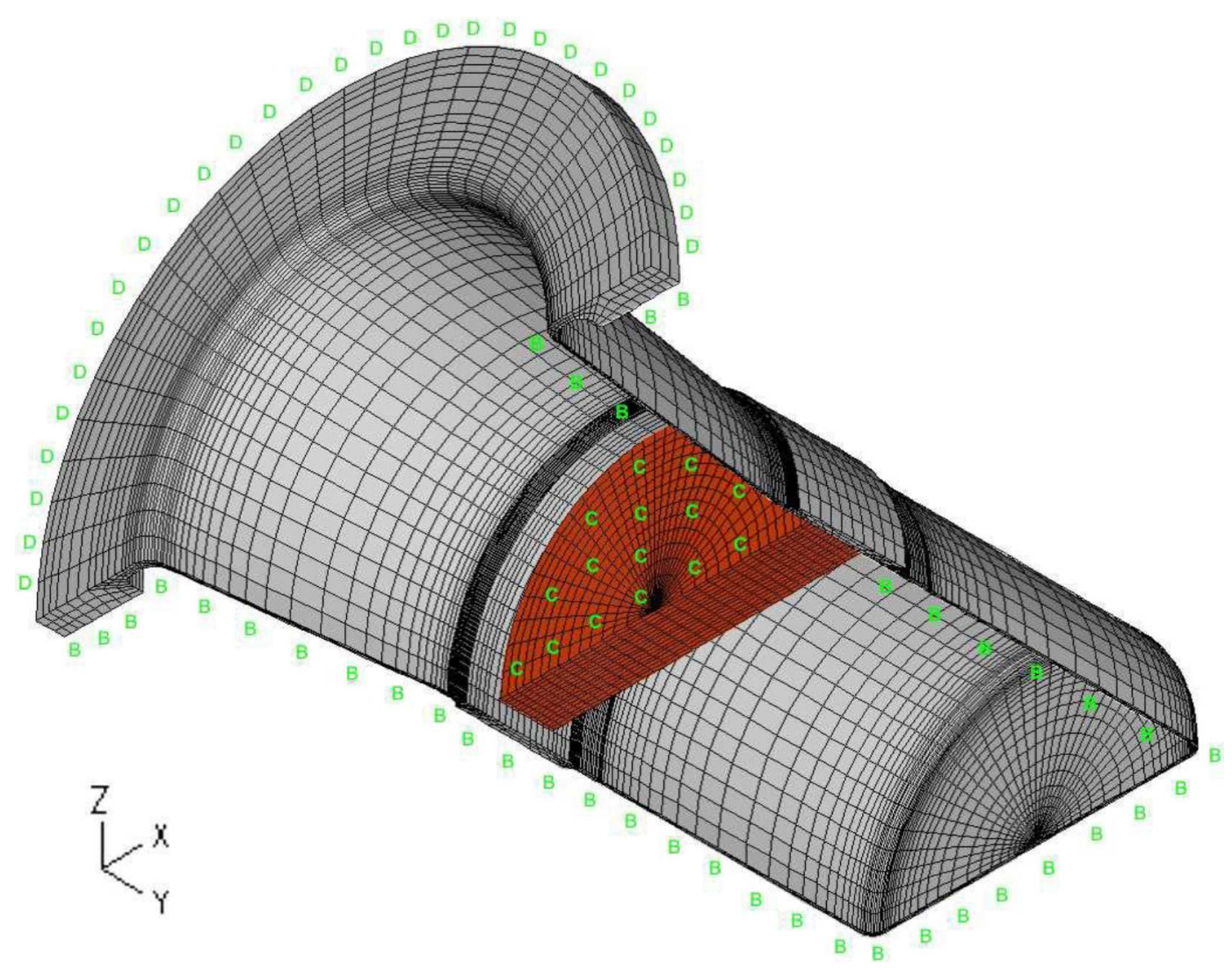

Fig. 3. The flexspline model prepared for calculations in ADINA

The described flexspline model of the hermetic harmonic drive was prepared in the program Mechanical Desktop and imported to ADINA. In order to maintain the actual character of operation, some degrees of freedom were taken away from a few fragments of the model. The nodes located in the cutting plane along its length (marked as B in Fig. 3) were allowed to move only in the $X Y$ plane. The nodes located on the flexspline flange (marked as D in Fig. 3) were fixed. The axis $Z$ of the prepared calculation model corresponds to the major axis of the generator, and the axis $X$ to the minor axis of the generator. The generator can only move towards the axis $Z$ (C in Fig. 3 ) by the value equal to the deformation $w_{0}$. The contact elements were defined between the flexspline and the generator so that the flexspline model could be precisely deformed to the desired shape, adequate for the cam generator. The torsional loading was defined in the ring which replaced the toothed rim in the meshing area corresponding to the actual harmonic drive. In the FEM calculations, the flexspline was under torsional loading of $T_{2}=150 \mathrm{Nm}$.

The calculations for such prepared models were conducted in the solver of ADINA and the obtained results were used as a basis for the analysis of the impact of the flexspline structure on its durability. 


\section{The analysis of the solution}

It was attempted to lower the maximum stress values through the change of the structural shape of the body of the flexspline of the hermetic harmonic drive. The changes were introduced under consideration that the analysed flexspline is the longest gear in the harmonic drive. Therefore, the possibility of reducing its length was analysed. The analysis was conducted on gears with various shapes of the body but with the same parameters of operation. During the analysis, many various models of the flexspline were taken into consideration. However, the results were presented only for five of them - for whom the most characteristic distribution of the reduced stress was obtained. Figures 4-8 presents the calculation results. The models which correspond to the consecutive structural variants of the flexspline are presented together with the obtained stress distributions. Variant I (Fig. 4) presents the flexspline designed according to recommendations most frequently offered in various publications. The flexspline of that shape has the least complex structure and it can be constructed most easily.

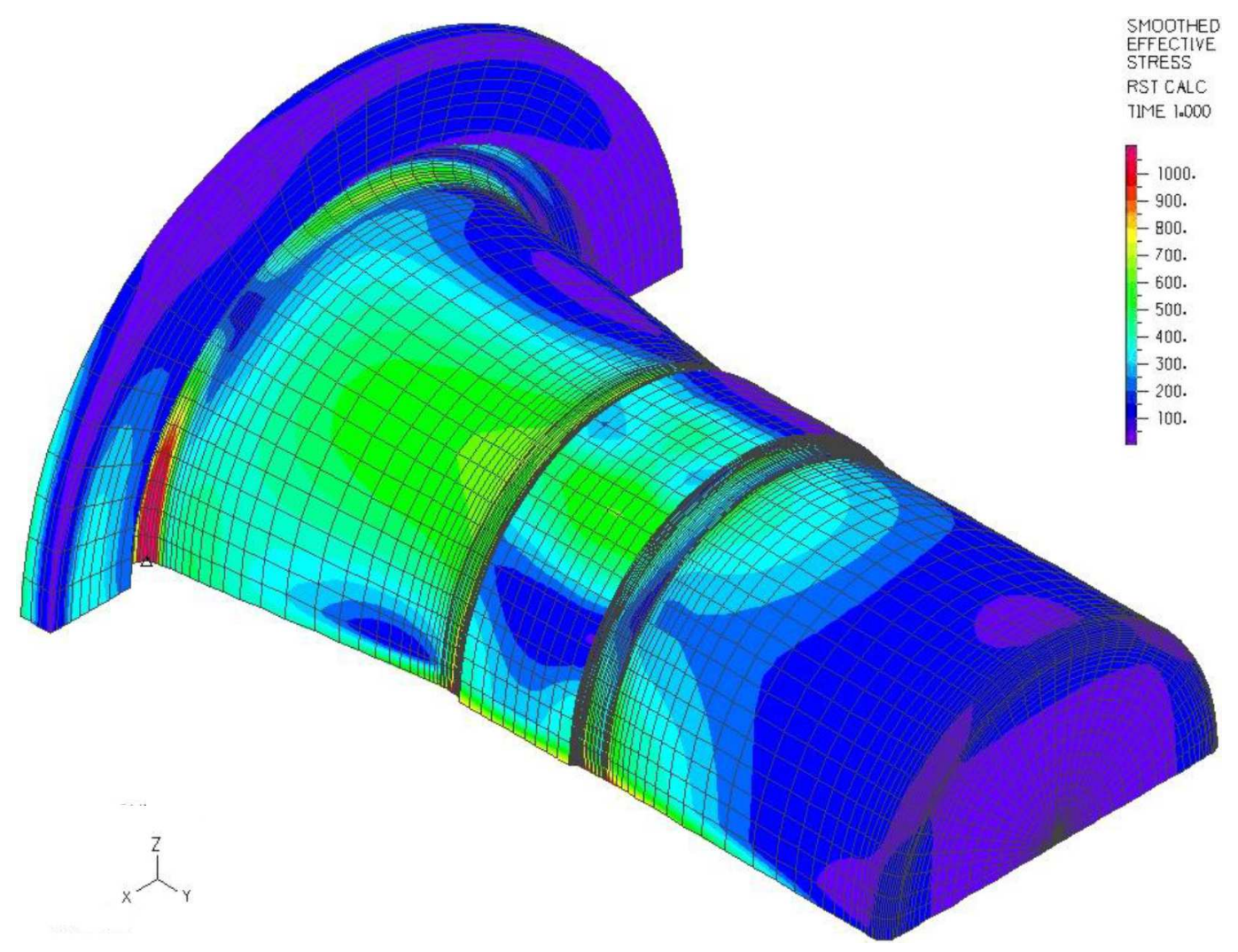

Fig. 4. The distribution of the reduced stress $\sigma_{z}[\mathrm{MPa}]$ in the flexspline model - variant I

Variant II of the flexspline (Fig. 5) has also been presented in the literature (Artjuchin et al., 1968). However, despite the favourable distribution of stress, it is not very often used due to structural problems. Moreover, with such a flexspline structure, the rigid gear has to be constructed as a sectional gear which, additionally, complicates the process of construction.

Variant III of the flexspline (Fig. 6) is a combination of the constructions used for variant I and variant II. The part of the flexspline between the flange and the toothed rim was constructed in the same way as for variant II due to the favourable stress distribution. The part of the flexspline between the toothed rim and the bottom was considered as cylindrical due to the fact that the stress is not considerable and the cylindrical shape is the least problematic during the process of construction. 


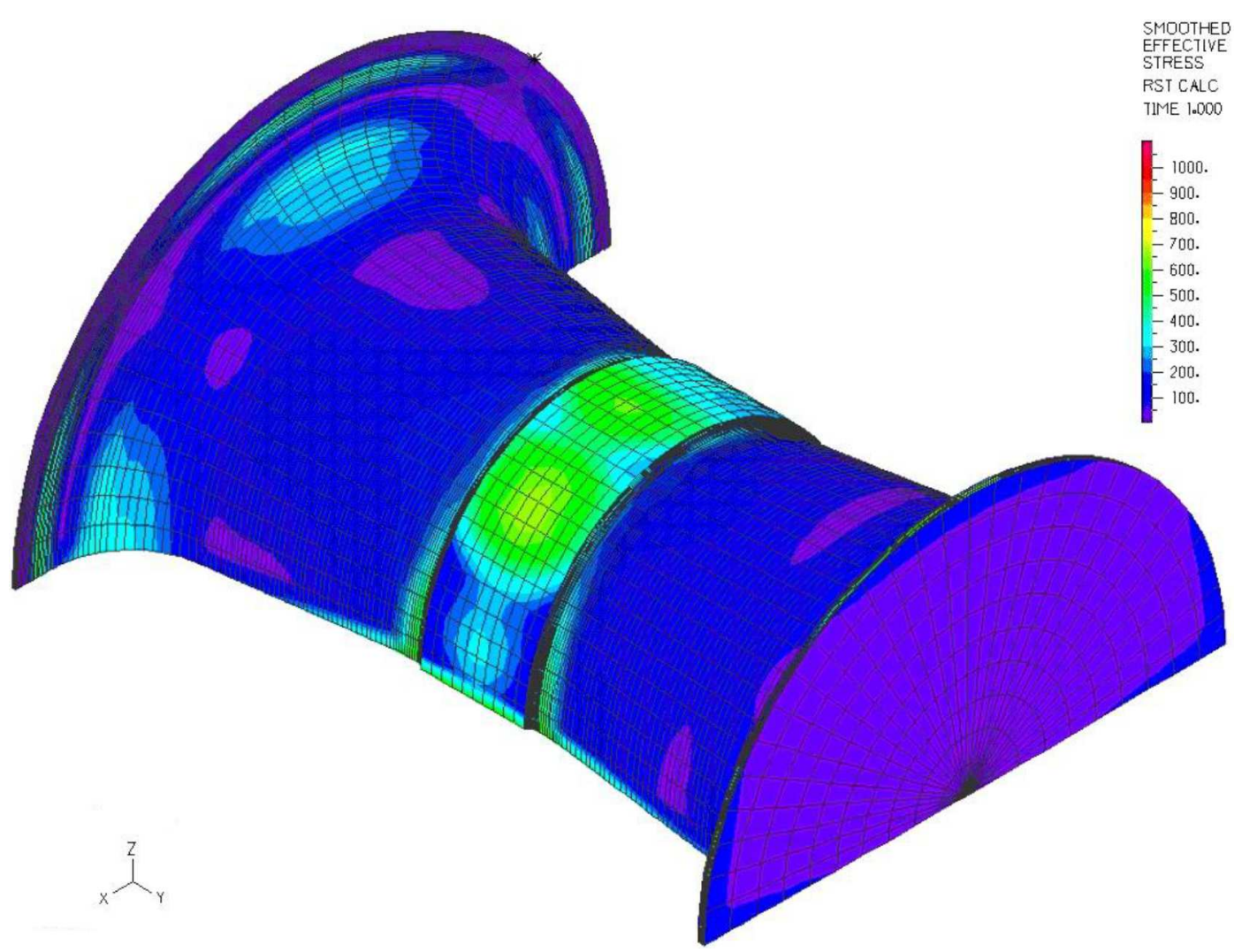

Fig. 5. The distribution of the reduced stress $\sigma_{z}[\mathrm{MPa}]$ in the flexspline model - variant II

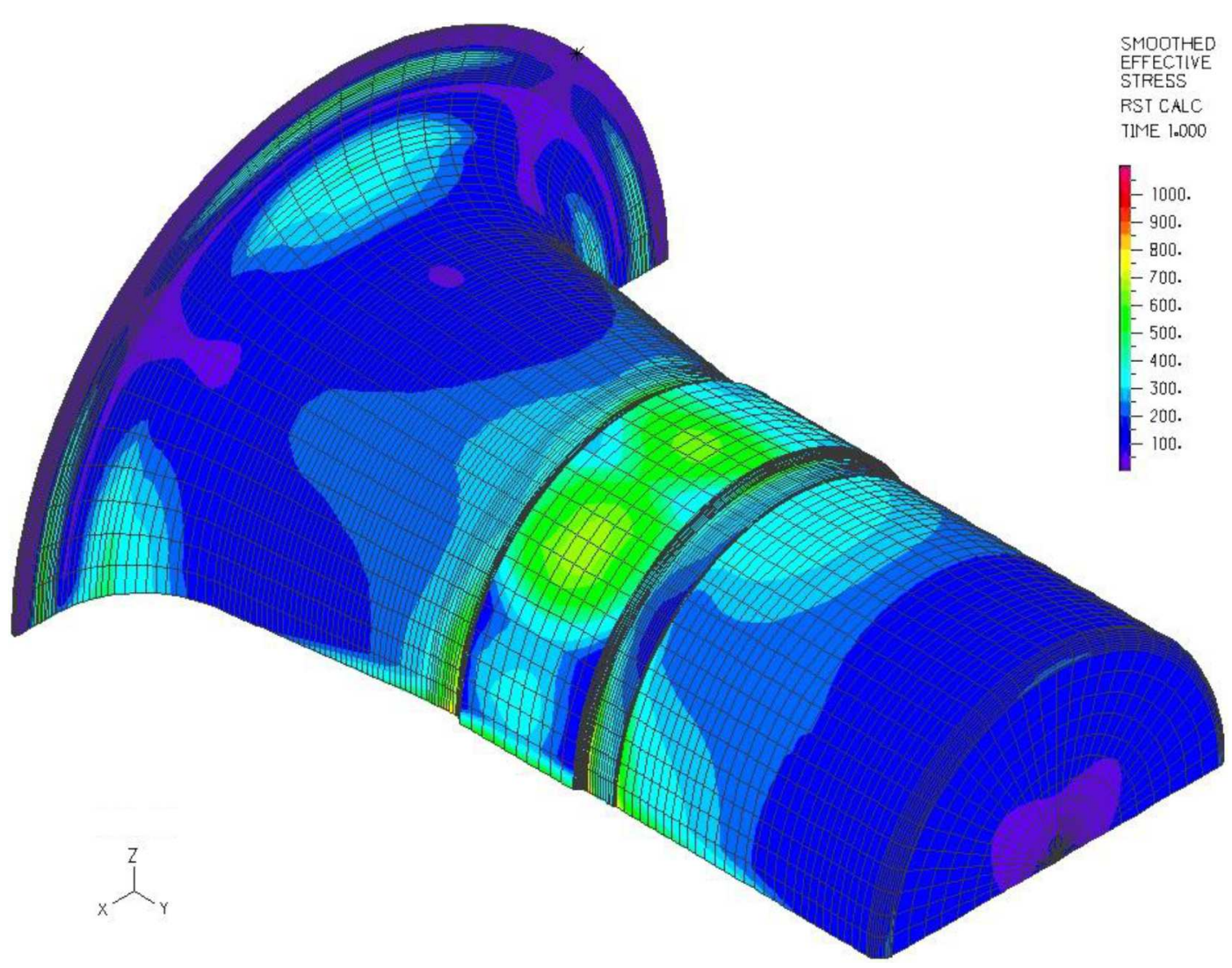

Fig. 6. The distribution of the reduced stress $\sigma_{z}[\mathrm{MPa}]$ in the flexspline model - variant III 


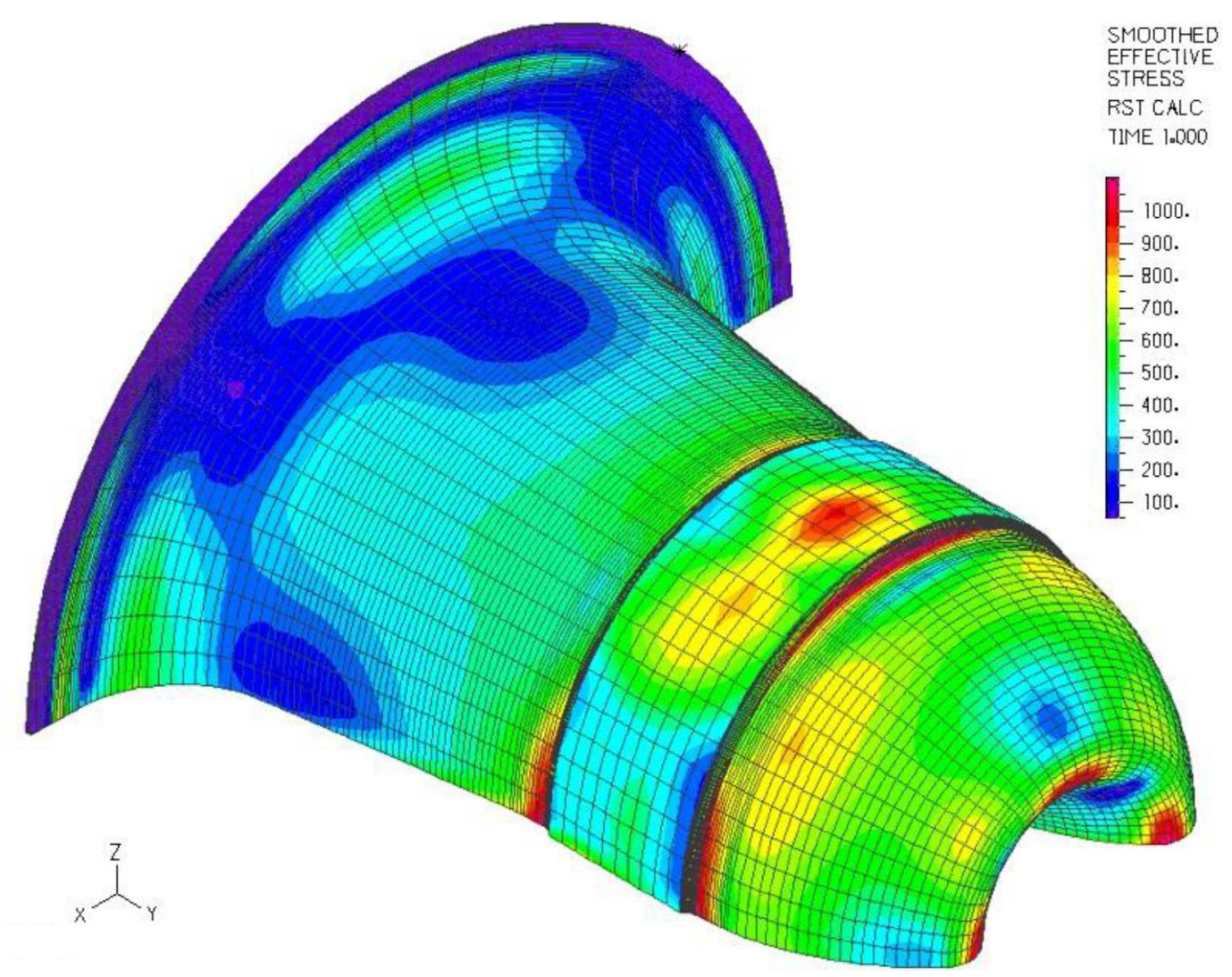

Fig. 7. The distribution of the reduced stress $\sigma_{z}[\mathrm{MPa}]$ in the flexspline model - variant IV

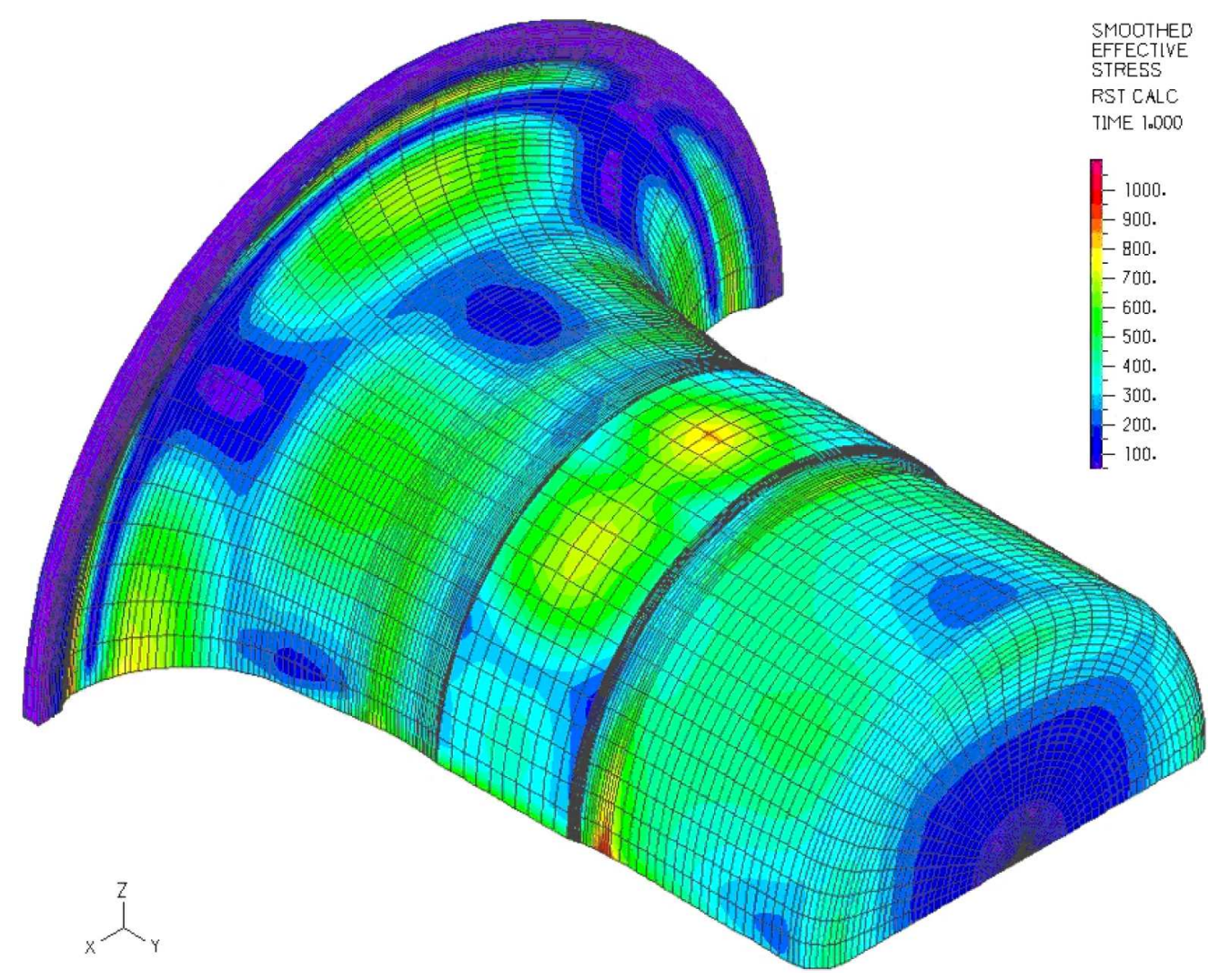

Fig. 8. The distribution of the reduced stress $\sigma_{z}[\mathrm{MPa}]$ in the flexspline model - variant $\mathrm{V}$ 
Variant IV (Fig. 7) differs from the previous variant in terms of the shape of the bottom. In this structural solution, the flat bottom was changed into a shape which allowed one to obtain reduced length of the flexspline.

Both, variant II and IV are recommended in the literature as new structures. However, the research confirming the desirability of their application was presented for none of them.

Variant V (Fig. 8) was constructed after selection of those structural solutions from previous variants which resulted in a reduction of the maximum stress values as well as reduction of the total flexspline length. The most important changes concerned the shape of the conical part which was constructed in the same way as in variants II, III and IV but it was shorter by $25 \mathrm{~mm}$. The part of the flexspline between the toothed rim and the bottom was constructed as cylindrical, similarly as in variant I, but it was shortened by $20 \mathrm{~mm}$.

During the calculations, the toothed rim was replaced with a ring in the simplified models of the flexspline. Therefore, only the results for stress distribution in the body of the flexspline were taken into consideration. In the presented calculation results, for all variants of the flexspline, we can observe the occurrence of the highest levels of stress on the major and minor axis of the generator in the areas of the toothed rim and flange of the flexspline. A particularly high stress level occurs on the radius between the conical part and the flange in variant I which, in the case of other variants, was considerably reduced thanks to the increasing of the radius.

The most favourable distribution of the reduced stress occurs in variant II where the maximum stress values are lower than $500 \mathrm{MPa}$. However, the construction of the gear in this shape is more complicated. Therefore, we may encounter a lot of similar structural solutions where the gear is composed of several fragments that are connected one to another or structures with a welded bottom.

In variant III, thanks to the use of a larger radius at the flange, the stress values were lower in the conical part. However, the stress level in the areas of the toothed rim were still as high as $700 \mathrm{MPa}$ on the radius between the toothed rim and the body.

In the simplified models (variant IV and V), high stress levels could also be observed in the areas of the bottom, in the part between the toothed rim and the bottom of the flexspline as well as in the middle of the conical part. In those models, the stress values were also high in the intersection at the angle of $\varphi=45^{\circ}$ to the major axis of the generator. In the case of the flexspline constructed according to variant IV and V, thanks to its smaller size, we can design smaller drives. However, additional research should be conducted as the use of shorter flexsplines is expected to worsen the engagement between teeth of the flexspline and rigid gear.

In order to conduct the quantitative analysis, graphs of the reduced stress in a longitudinal intersection (which passes through the major axis of the generator for all presented variants) were prepared. When put together, the graphs (Fig. 9) may be used in the evaluation of the impact of the respective structural solutions on the stress level and its distribution in the analysed models on the basis of FEM calculations.

A very unfavourable stress distribution occurred in variant IV. In this case, the stress exceeded the level of $1000 \mathrm{MPa}$, which disqualifies this solution especially when we compare it to other models. For the remaining structures, the reduced stress does not exceed the level of $700 \mathrm{MPa}$. Variant II requires particular attention because, in its analysis, the toothed rim was excluded, and the highest stress occurred in the areas of the flange and reached the value of $382 \mathrm{MPa}$. For the remaining variants, the maximum stress values were higher than in variant II. It needs to be emphasised that in variant I (most frequent in the literature) the stress values are higher than in the case of the majority of the considered variants. This means that there are great possibilities of finding new structures of flexsplines of the hermetic drives.

As a part of the research on the impact of the body shape of the flexspline on the stress distribution, the effect of various structures in the toothed rim areas was also analysed. The stress calculations were conducted for the models constructed according to variant III and variant IV. 

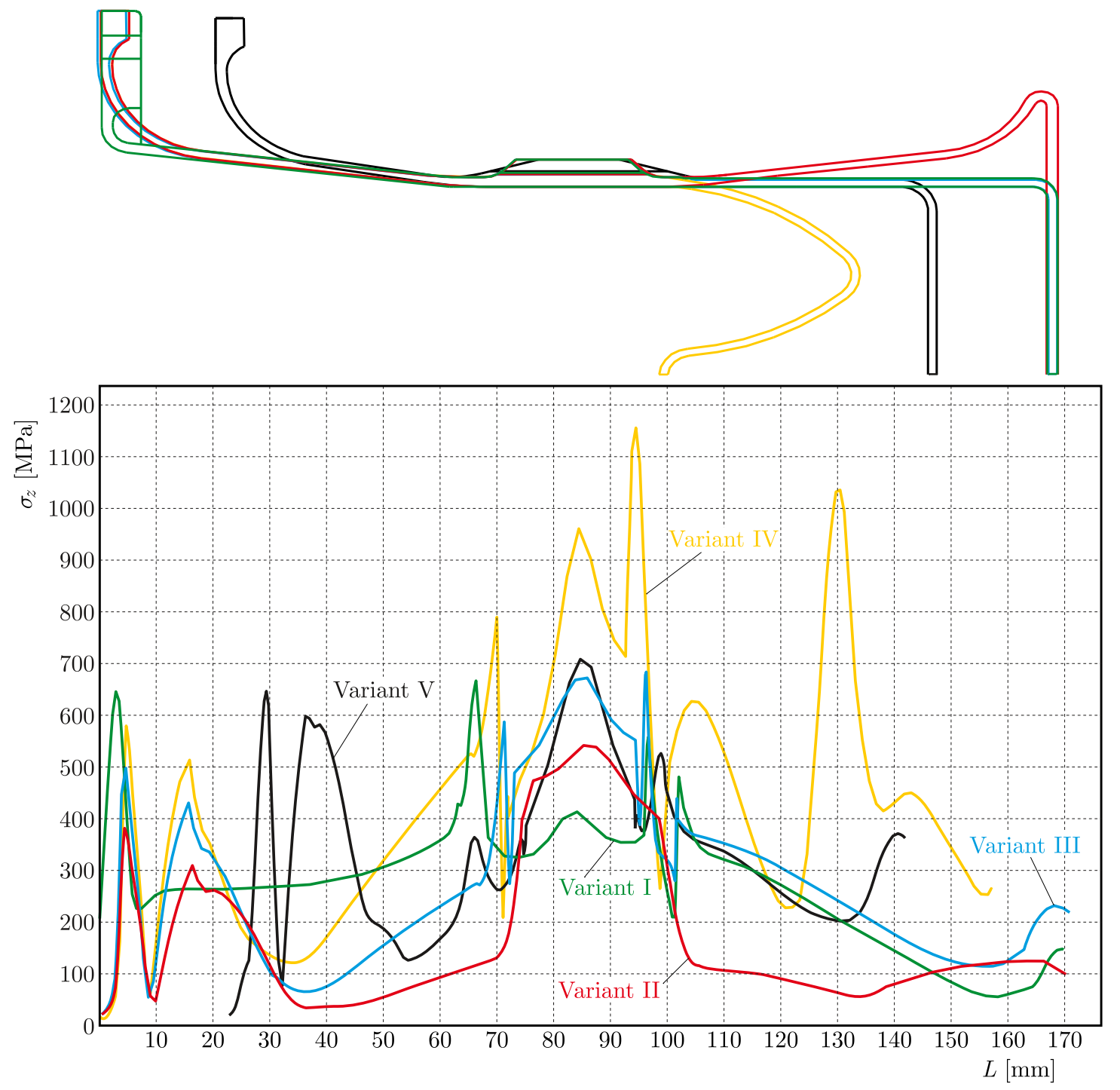

Fig. 9. Reduced stress $\sigma_{z}$ in the longitudinal intersection which passes through the major axis of the generator for variant I and variant IV of the flexspline structure

In each of them, the toothed rim structure of type 1 and 2 was used according to Fig. 10. No other measurements were changed.

Type 1 solution is frequently discussed in the literature (Danilov, 1983; Mijał, 1999; Muller and Wilk, 1965). However, due to a double change in thickness of the flexspline, unnecessary concentration of stress in this area occured. Therefore, it was attempted to reduce the consequences of the notch effect, and smooth conical reduction of the diameter was suggested (type 2).

To construct flexsplines according to variant III and IV, the closest area of the toothed rim was thickened (see Fig. 10a). Next, it was calculated again for the solution presented in Fig. 10b.

(a)

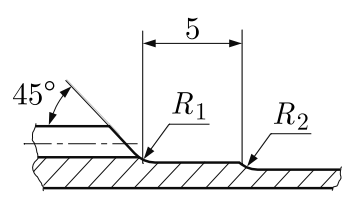

(b)

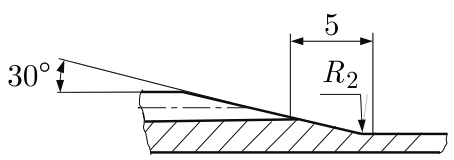

Fig. 10. The structure of the toothed rim of the flexsplines: (a) type 1, (b) type 2 
Figures 11 and 12 present graphs of the reduced stress in longitudinal intersections which pass through the major axis of the generator for the analysed flexspline models.

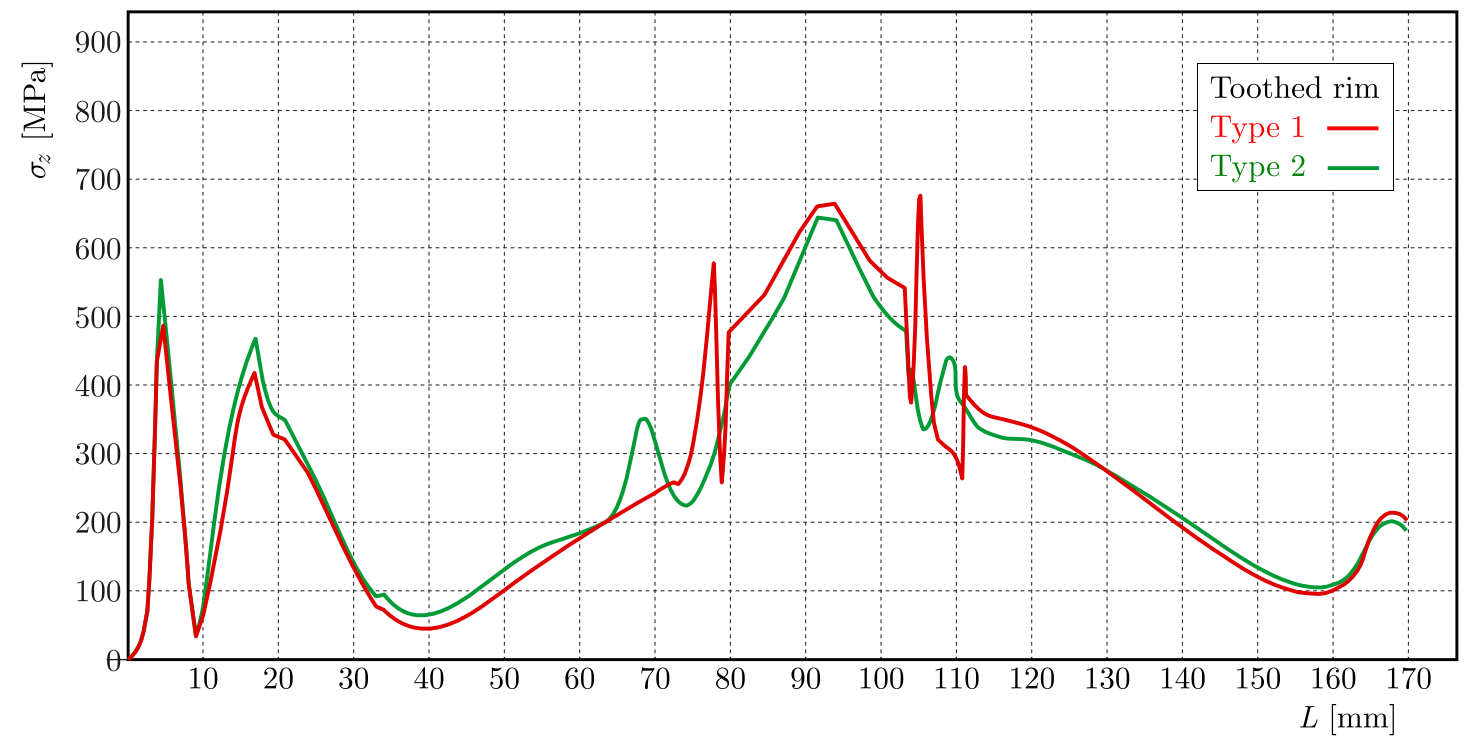

Fig. 11. The distribution of the reduced stress $\sigma_{z}$ in the longitudinal intersection which passes through the major axis of the generator of the flexspline model - variant III

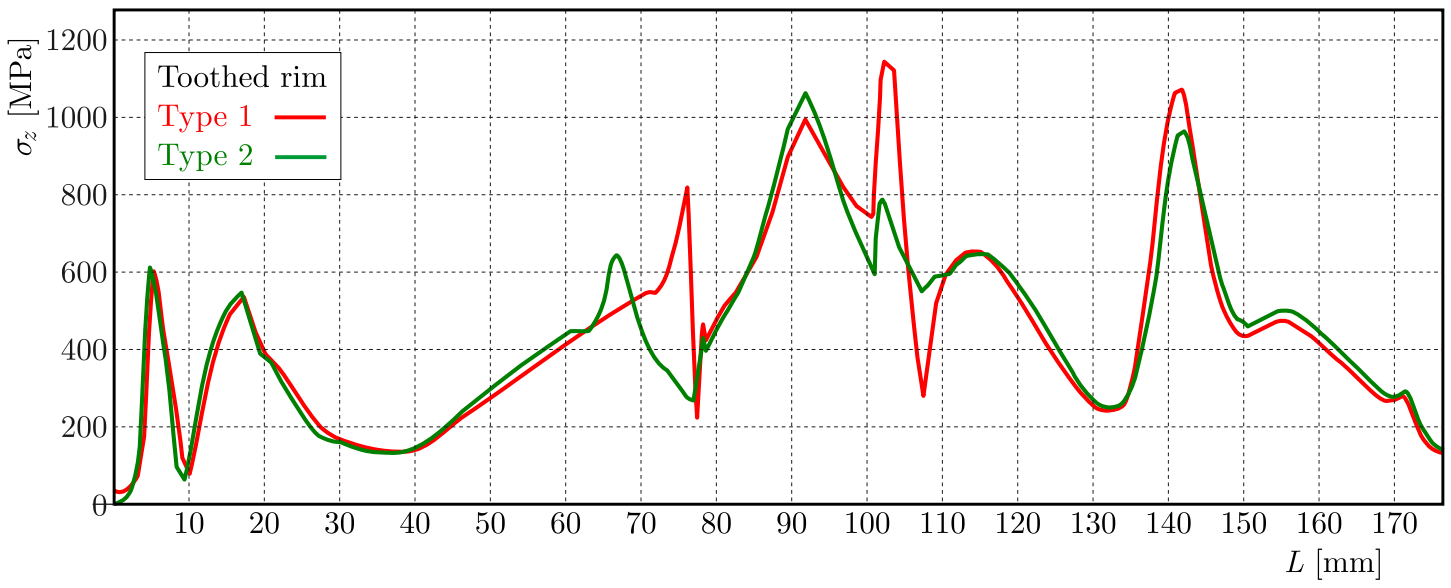

Fig. 12. The distribution of the reduced stress $\sigma_{z}$ in the longitudinal intersection which passes through the major axis of the generator of the flexspline model - variant IV

The construction of the flexspline according to solution of type 2 resulted in the lowering of the stress values in the areas of the toothed rim, i.e. in the modified area, whereas in the remaining fragments of the flexspline there were no significant changes in the graphs presented above. Apart from the lowering of the level of the maximum reduced stress, the structural change of the toothed rim resulted in moving away the area of higher stress values from the toothed rim (D in Figs. 11 and 12) which had a positive impact on the flexspline durability.

\section{Conclusions}

Among the analysed structures of the flexspline, the most favourable is variant II due to its durability. However, its structure is more complex. The flexsplines of the hermetic harmonic drive in variant III and V are technologically simpler, however, they do not have such a favourable 
stress distribution. The flexspline in variant $\mathrm{V}$ is $26.5 \%$ shorter than in the case of variant III and, therefore, it is recommended in the situation when there is a need to reduce the size of the hermetic harmonic drive. However, it needs to be pointed out that for such drives (with short flexsplines) there might be a problem with gear mating in the meshing area. In the situation when the kinematic accuracy needs to be taken into consideration, variant $\mathrm{V}$ of the flexspline body should be recommended. Variant I and III of the flexspline body structure is not recommended due to the occurrence unfavourable distributions and high stress levels. When calculating geometrical parameters of the toothed rims, we need to avoid solutions in which there is a possibility of the occurrence of stress accumulation such as, e.g., small curve radii or a substabtail change in thickness of the body. In the end, on the basis of the conducted analysis, the shape of the toothed rim area was suggested and it was presented in Fig. 10b. This structure significantly limits the level of maximum stress values in the area of the toothed rim and it does not create stress accumulations which are very unfavourable for durability of the structure. It needs to be remembered that FEM numerical calculations need to be verified. The accuracy of the results can be confirmed through their comparison with calculations conducted with another method or research on actual structures. The FEM analysis is conducted on simplified models and the obtained results, to a great extent, depend on the correct process of model discretisation. The numerical analyses, which include FEM methods, allow one to considerably escalate the process of design of the toothed gear and, very often, to receive results which, otherwise, cannot be obtained in analytical calculations. Computational durability analyses allow one to design flexsplines with new optimized shapes which will carry larger load or improve durability of harmonic drives. It is a crucial issue as flexsplines have complex structures and, as the fundamental element which carries the biggest load, they decide about the reliability of the entire drive and, therefore, about the viability of its use. New structural solutions of the hermetic harmonic drives provide the possibility to increase the scope of their use in the aviation, space and chemical industry, and whenever it is necessary to maintain vacuum and airtightness.

\section{References}

1. Artuduhin W. A., Kaspierowic N. S., Ciecina M. N., 1968, Machine Design. Design Catalogue (in Russian), Mashinostrojenie, Moskva

2. Budzik G., Pacana J., 2005, Stress analysis in the flexspline ring in a hermetic harmonic drive (in Polish), Western Center of the Ukrainian Academy of Transport, 12, 148-150

3. BudzIK G., KozIK B., PACANA J., 2009, Determinig of model similarity for flexspline of harmonic drive with the use of FEM and extensometer method, Journal of KONES Powertrain and Transport, 16, 55-60

4. Danilov A.J., 1983, Recommendation for construction of membranes with complex curvatures in harmonic hermetic drives (in Russian), Mashinovedenije, 4, 67-71

5. Dudley D.W., 1962, Harmonic Drive Arrengements, Gear Handbook, McGraw-Hill Publishing Co. $3-35$ to $2-43$

6. Folęga P., 2009, Numerical stress analysis of harmonic drive elements by BEM, Problemy Eksploatacji, 1, 85-92

7. Folfiga P., 2015, Computer-Aided Engineering of Selected Gear Transmission Elements (in Polish), Publishing House of the Silesian University of Technology, Gliwice

8. Gravagno F., Mucino V.H., Pennestri E., 2016, Influence of wave generator profile on the pure kinematic error and centrodes of harmonic drive, Mechanism and Machine Theory, 104, $100-117$

9. Ishikawa S., 1967, The gear geometry of tooth engagement in harmonic drive, Proceedings of the JSME Semi-International Symposium, Tokyo, 94-104 
10. JEOn H.S., OH S.H., 1999, A study on stress and vibration analysis of a steel and hybrid flexspline for harmonic drive, Composite Structures, 47, 827-833

11. Kayabasi O., Erzincanli F., 2007, Shape optimization of tooth profile of a flexspline for a harmonic drive by finite element modeling, Materials and Design, 28, 441-447

12. Kikuchi M., Nitta R., Kiyosawa Y., Zhang X.Y., 2003, Stress analysis of cup type strain wave gearing, Key Engineering Materials, 243-244, 129-134

13. Kleiber M., Zacharski A., 1983, Effective nonlinear analysis of arbitrary thin shells by simple finite elements, Mechanika Teoretyczna $i$ Stosowana, 21, 1, 25-46

14. Li S., 2016, Diaphragm stress analysis and fatigue strength evaluation of the flex-spline, a very thin-walled spur gear used in the strain wave gearing, Mechanism and Machine Theory, 104, 1-16

15. Mijaє M., 1996, Harmonic hermetic drive (in Polish), Proceedings of Seminar - Special Mechanical Gears, IPBM University of Warsaw, 105-110

16. Mijat M., 1999, Synthesis of Harmonic Drives (in Polish), Publishing House of the Technical University of Rzeszow, Rzeszow

17. Miją M., Pacana J., 2004, Hermetic harmonic gear drive with welded flexspline, Western Center of the Ukrainian Academy of Transport, 11, 160-162

18. Muller L., Wilk A., 1965, Drives with flexible ring, Przeglad Mechaniczny, 20

19. Musser C.W., 1960, The harmonic drive, Machine Design, 32, 8

20. Ostapski W., 2011, Harmonic Drive (in Polish), Publishing House of the Warsaw University of Technology, Warsaw

21. Pacana J., 2018, Strength Analysis for Gear Transmissions Using FEM (in Polish), Publishing House of the Technical University of Rzeszow, Rzeszow

22. Pacana J., Budzik G., 2008, Analysis of the correctness FEM solution depending on the type and number of finite elements used (in Polish), Acta Mechanica Slovaca, 12, 3-A, 327-332

23. Pacana J., Markowska O., 2016, The analysis of the kinematic accuracy of the actual harmonic drive on a test bench, Advances in Manufacturing Science and Technology, 1, 47-54

24. PN-79/N-88514 Reduktory zębate ogólnego przeznaczenia - nazwy i określenia (General purpose gear reducers - names and definitions)

25. Tuahjowidodo T., Al-Bender F., Van Brussel H., 2013, Theoretical modelling and experimental identification of nonlinear torsional behaviour in harmonic drives, Mechatronics, 23, 497-504 